\title{
MULTIPLE FOREIGN BODIES IN THE ANTERIOR AND POSTERIOR URETHRA
}

\author{
TROY SUKKARIEH, MARC SMALDONE, BHARAT SHAH \\ Northport Veterans Affairs Medical Center, Northport, New York, USA
}

\begin{abstract}
Foreign bodies of the urethra and bladder are seen with iatrogenic injury, self-insertion, and rarely migration from adjacent sites. Treatment is focused on foreign body extraction, diagnosing complications, and avoiding compromise of erectile function. With advances in endourology, the majority of cases can now be managed endoscopically. We present a case of a man with multiple foreign bodies located both above and below the urogenital diaphragm. Advancing the posterior objects intravesically and extracting with a stone basket accomplished successful removal.
\end{abstract}

Key words: urethra; bladder; foreign body; endoscopy

Int Braz J Urol. 2004; 30: 219-20

\section{INTRODUCTION}

Foreign bodies of the urethra and bladder are seen with iatrogenic injury, self-insertion, and rarely migration from adjacent sites. Treatment is focused on foreign body extraction, diagnosing complications, and avoiding compromise of erectile function (1-4).

\section{CASE REPORT}

A 59-year-old male presented to the emergency room with dysuria and urinary dribbling. After questioning, he noted inserting multiple small metal objects into his urethra. Patient denied any fevers or chills. He was able to dribble blood tinged urine with straining. The patient reported a history of major depression, but no history of self-injurious behavior. His physical examination was significant for a non-distended bladder, meatal stricture, and multiple palpable foreign bodies from the glans penis to the penoscrotal junction. X-rays of the pelvis showed multiple metallic objects approximately $1 \mathrm{~cm}$ in diameter in the anterior and posterior urethra (Figure-1).
The patient was taken to the operating room after receiving pre-operative intravenous antibiotics. After performing a meatotomy, a total of 10 metallic objects in the anterior urethra were milked out and delivered from the urethra. A cystoscopic examination was performed which demonstrated multiple metallic

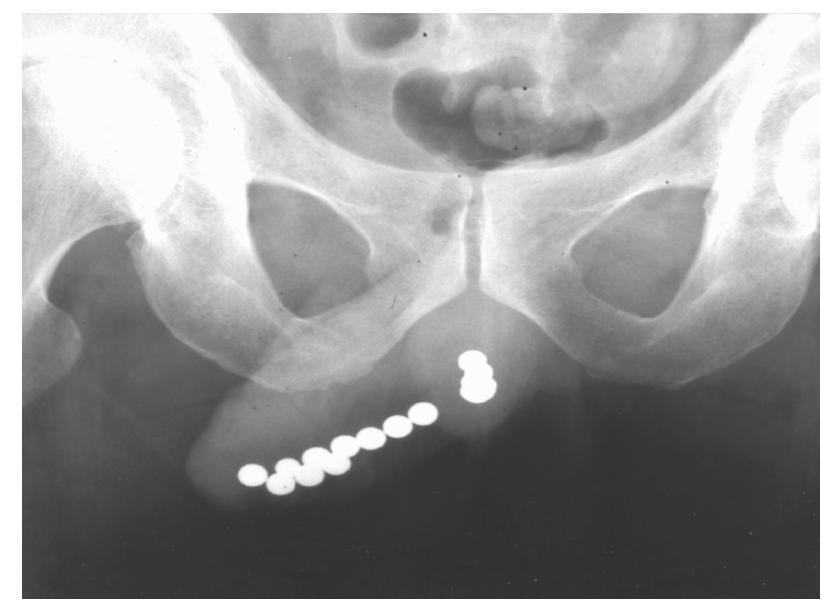

Figure 1 - X-ray of the pelvis showed multiple metallic objects approximately $1 \mathrm{~cm}$ in diameter in the anterior and posterior urethra. 
objects in the proximal urethra. These objects were pushed into the bladder using the cystoscope. After this, the metallic objects were individually removed using a three-prong stone basket. An 18F urethral catheter was kept in place for 24 hours. The patient received a complete inpatient psychiatric evaluation post-operatively. He was subsequently discharged home after successfully voiding.

\section{COMMENTS}

Foreign bodies are most commonly inserted into the genitourinary tract by psychiatric, intoxicated, confused, or sexually curious patients. It has also been documented that well-adjusted patients without concomitant psychiatric illnesses have attempted to relieve urinary retention or itching by inserting objects into the urethra.

Co-morbidities reported in patients presenting with foreign body insertion include exotic impulses most commonly sexual in nature, mental illness, borderline personality disorder, and intoxication. Alibadi et al. (4) reported that reasons for self-instrumentation in their population of 18 patients included auto-eroticism in 6 (33\%), overt psychiatric causes in $2(11 \%)$, to aid in voiding in 7 (39\%), and in 3 patients (17\%) no definite reason could be ascertained.

The presenting symptoms reflect irritation of the lower genitor-urinary tract with the most common being dysuria, lower abdominal and urethral pain, microscopic or gross hematuria, acute urinary retention, urethral discharge, and fevers (1-4). Diagnosis can frequently be determined by clinical history and careful physical examination. Objects located distal to the urogenital diaphragm can typically be palpated directly, while objects proximal to the diaphragm are not readily palpable. If the diagnosis is unclear, radiopaque foreign bodies can be localized with plain X-ray film examination supported by endoscopic examination, while excretory urogram or cystograms and ultrasound imaging may reveal radiolucent objects.

The main objectives of treatment include diagnosing complications, foreign body extraction, and avoiding compromise of erectile function. Endoscopic manipulation and extraction utilizing forceps and snares, balloon-wires, and stoneretrieving baskets have been documented as successful in the removal of foreign objects located below the urogenital diaphragm. Due to the high incidence of co-morbid psychiatric disease, mental retardation, and dementia, it has been suggested that patients presenting in this manner have routine psychiatric evaluation, although this had not been universally agreed upon.

\section{REFERENCES}

1. Gonzalgo ML, Chan DY: Endoscopic basket extraction of a urethral foreign body. Urology. 2003; 62:352.

2. van Ophoven A, deKernion JB: Clinical management of foreign bodies of the genitourinary tract. J Urol. 2000;164: 274-87.

3. Quin G, McCarthy G: Self insertion of urethral foreign bodies. J Accid Emerg Med. 2000; 17: 231.

4. Aliabadi H, Cass AS, Gleich P, Johnson CF: Selfinflicted foreign bodies involving lower urinary tract and male genitals. Urology. 1985; 26: 12-6.

Received: September 29, 2003

Accepted after revision: December 22, 2003
Correspondence address:

Dr. Troy Sukkarieh

Department of Urology

Health Sciences Center T-9 Room 040

University Hospital and Medical Center

Stony Brook, NY 11794-8093, USA

Fax: + 1631 444-7620

E-mail: tsukkarieh@yahoo.com 